\title{
Introducing the Innovation-Alignment-Portfolio to Balance Exploitation and Exploration of Innovations
}

\author{
Günter Hofbauer \\ Technische Hochschule Ingolstadt, Ingolstadt, Germany \\ Karina Hofbauer \\ Universität Regensburg, Regensburg, Germany
}

\begin{abstract}
Research in the field of innovation is very important, because innovations are necessary prerequisites for the success of companies. Innovation management has to be executed in consideration of external influences (environment) and internal influences (company). The research topic is about optimizing the budget allocation for innovation management. The main research question is how to decide between the two basic options: exploitation and exploration. A promising way is to balance these two antipodes. One extent is to do research and development to explore new knowledge and create basic innovations as well as to use new technologies to invent new products (exploration). The other extent is to fully utilize and exploit existing possibilities, potential, and technologies (exploitation). It is a crucial management task to find the right balance between these two proceedings. To answer the research question is how to balance exploration and exploitation in an adequate way. The applied method is literature research and analytical development of a tool, which should help to find the right management decision about innovation strategy and budget allocation. This article is a conceptual paper with a deductive approach, in which the framework of variables influencing the decision about exploration and exploitation is introduced and in which the Innovation-Alignment-Portfolio (IAP) as a tool to substantiate the decision between the two antipodes is presented. As a result, the specific contribution to academic discussion, based on critical literature review, is twofold: firstly, deployment of a systematic framework of antecendents and tradeoffs influencing the management decision. Secondly, the development and introduction of the Innovation-Alignment-Portfolio. The structure of the paper consists of three main parts. The first part is about the introduction and problem formulation. In the second part, a critical literature review is done and leads to the research results, which are summarized in the framework of innovation management. Factors of influence are analyzed and discussed. In the third part, the Innovation-Alignment-Portfolio is introduced as a tool to balance exploration and exploitation. The conclusion of this paper is that decisions about innovation strategies can be made in a more differentiated way by using the Innovation-Alignment-Portfolio.
\end{abstract}

Keywords: antecendents, exploration, exploitation, innovation, Innovation-Alignment-Portfolio

Günter Hofbauer, prof., Ph.D., full professor, Technische Hochschule Ingolstadt, Ingolstadt, Germany.

Karina Hofbauer, B.Sc., University of Regensburg, Regensburg, Germany.

Correspondence concerning this article should be addressed to Günter Hofbauer, Technische Hochschule Ingolstadt, Business School, Esplanade 10, D-85049 Ingolstadt, Germany. 


\section{Introduction and Problem Formulation}

Innovations are the engine of economic prosperity and wealth. Innovations require permanent effort for renewal, they are essential for success and competitiveness (Hofbauer, Körner, Nikolaus, \& Poost 2009). Being innovative means to be able to modernize the product portfolio and to adapt products to changing demand (Gandhi \& Hofbauer, 2016). In order to put these issues into execution, it is inevitable to analyze and recognize the signals from the environment and to transfer this information into appropriate managerial actions. In this context especially referring to exploration and exploitation of innovation. Figure 1 shows the dimensions, which have to be analyzed.

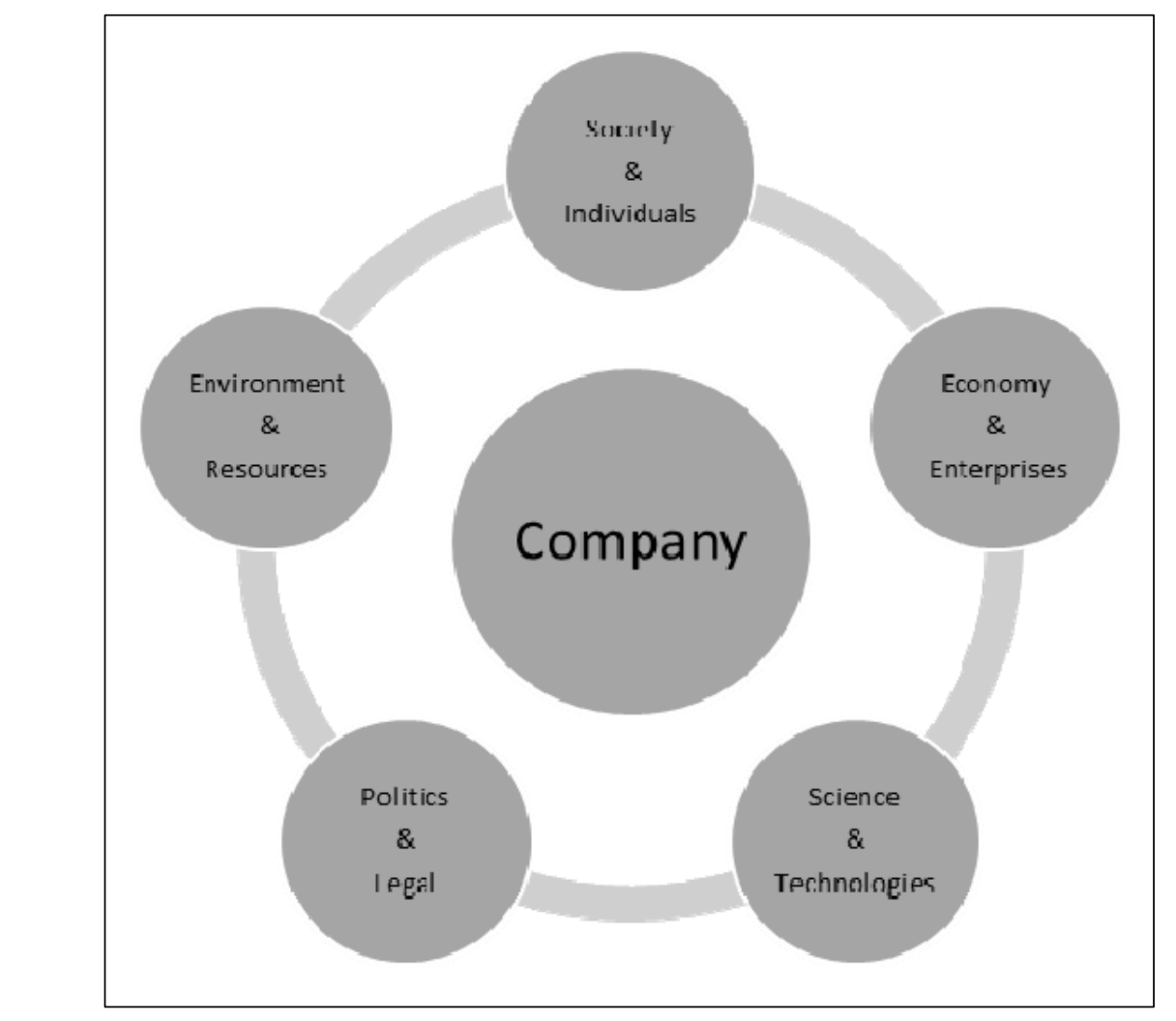

Figure 1. System of external factors influencing innovation management. Source: Siemens (2014).

The scope of this article is to do critical research on existing literature about exploration and exploitation of innovation. The crucial research question is how to stimulate and promote the evolvement of exploration and exploitation in an adequate constellation. Based on the literature review, the framework of antecedents, tradeoffs, and outcome of innovation management will be explained. After that, the Innovation-Alignment-Portfolio as a supporting tool to balance exploration and exploitation in the best possible way will be introduced.

\section{Literature Review About Exploration and Exploitation of Innovations}

Exploration and exploitation belong to the fundamental terms of strategic knowledge management, which become more and more important for economic management as well as for innovation and product management (Hofbauer \& Sangl, 2011). A brief description shows the difference: "exploration as refinement, choice, production, efficiency, selection, implementation, and execution, contrasting it with exploitation, which 
involves search, variation, risk-taking, experimentation, play, flexibility, discovery, and innovation" (Lavie, Stettner, \& Tushman, 2010).

\section{Exploration of Innovations}

Companies need new products to operate successfully in the market. Therefore, they have to explore new potentials through new technologies (Hofbauer, 2013). By turning away from the existing knowledge, they create new knowledge and develop new capabilities in order to detect new chances and to develop previously unknown potentials. By doing this, companies are prepared to react to changing demand or even create new trends (Auh \& Menguc, 2005). Exploration is future-oriented and has a long term horizon, providing high potentials, but is also linked with high risk. Know how is designed in a botton-up learning process independently from existing knowledge and technology (Lubatkin, Simsek, Ling, \& Veiga 2006).

\section{Exploitation of Innovations}

By using exploitative proceedings, companies endeavor to use existing capabilities and technologies. This means to exploit available knowledge and existing technologies, know how, or networks (March, 1991). This will be possible by doing improvement, specialisation, selection, refinement, and experience. The adaptation to new constellations will be done by stepwise improvement (Gupta, Smith, \& Shalley 2006). Compared to exploration, the proceeding of exploration is oriented towards the past, because accumulated knowledge is used without reflection towards the future. Correspondingly, exploitative innovations have a short term horizon with low risk, but accordingly limited chances. Exploitation is executed in directed processes of search. In addition to that, companies tend to perpetuate practiced procedures and to institutionalize processes, which are adapted in an optimal way to existing competences. This procedure is well known as top-down learning process (Lubatkin et al., 2006).

\section{Survey of Characteristics}

Table 1

Characteristics of Exploration and Exploitation of Innovations

\begin{tabular}{|l|l|l|}
\hline & Exploration & Exploitation \\
\hline Strategy & $\begin{array}{l}\text { entrepreneurial, long term, technology and } \\
\text { innovation-oriented }\end{array}$ & efficient, short term, product and process-oriented \\
\hline Search & distant, far-out & nearby, close \\
\hline Knowledge & implicit & explicit \\
\hline Learning & double-loop, generative, feedback & single-loop, adaptive, feed-forward \\
\hline Innovation & radical, fundamental & incremental, improving \\
\hline Structures & $\begin{array}{l}\text { organic, decentralised, informal, open, } \\
\text { project-oriented }\end{array}$ & mechanistic, centralised, formal, closed, functional \\
\hline Controlling/Supervision & input driven, self monitoring, trust & output driven, process monitoring, results, contract \\
\hline Network & open, weak ties & closed, strong ties \\
\hline Management & $\begin{array}{l}\text { transformational, visionary, participative, } \\
\text { bottom-up }\end{array}$ & transactional, structural, authoritarian, top-down \\
\hline Culture & relationship oriented & task oriented \\
\hline
\end{tabular}

As mentioned above, the basic research method is critical literature review. As a result, there are some characteristics of differentiation, which help for a better understanding and distinction. Research results are summarized in Table 1 as typical characteristics of exploration and exploitation. The differences are illustrated by typical features distinguished by the means of the strategic management. 


\section{The Mutual Relationship of Exploration and Exploitation}

Another result of critical literature review is summarized in this section. In the subsequent remarks, the mutual relationship of the different proceedings will be focused. Tradeoffs, balancing, and ambidexterity are explained.

\section{Tradeoff Between Exploration and Exploitation}

There is an interrelation between explorative and exploitative proceedings (Gupta et al., 2006). The tradeoff relation between "Resource Exploration" and "Resource Exploitation" is in the focus of research since many years. In face of given differences, it is not easy to make a clear distinction and to give clear advice for one of the two proceedings (Lavie et al., 2010).

There is a crowding out between the two proceedings, because both need capacities and resources as well as management attention. Both approaches are competing for budgets. The budget allocated for exploration is not available for exploitation and vice versa.

There are two kinds of crowding out. On the one side, there is the Failure Trap, where exploration crowds out exploitation. This means that the explorative search is risky and causes possibly new failures. On the other side, there is the Success Trap, where exploitation crowds out exploration. Compared to the results of exploration, this procedure is more promising in the short term horizon.

\section{Balancing Exploration and Exploitation}

The long term oriented effectivity of exploration as well as the short term oriented efficiency of exploitation is essential for the sustainable success of a company. A one sided emphasis of the activity removes the possibilities of the other activity. For example, it is very risky to emphasize exploration and generate too less specific competencies or too much underdeveloped ideas. On the other side, a concentration on exploitation bears the danger to keep hold of too many outdated capabilities and resources. This could lead to short term success, but it would be at the expense of adaptability and competitiveness (Lavie \& Rosenkopf, 2006).

The mutual relationship has to be optimized that the internal resources can be allocated in the best way. The approach to solving this problem is to use both proceedings simultaneously by balancing benefits and disadvantages. Chen and Katila (2008) postulated: "some degree of balance is necessary for firm's survival and success".

Thus, one can derive that a positive interrelation can be very promising for the success of a company. This kind of relationship is called ambidexterity and means balancing the positive results.

\section{Ambidexterity}

Ambidexterity is an established term in the context of using exploration and exploitation to a certain extent (Lubatkin et al., 2006). This means that existing resources are used simultaneously subdivided for the different tasks (resource exploitation) to create the highest value (alignment) (O'Reilly \& Tushman, 2004). Therefore, there is a need for a strong efficiency orientation to develop new resources (resource exploration) to be able to adapt to changes of the environment (adaptability). This requires a high flexibility to use "diverging logics" or “competing frames" (Proff \& Haberle, 2010).

There are a lot of comprehensible reasons to balance exploration and exploitation in order to foster innovation activities (Wollersheim, 2010). In this respect, each innovating company faces the challenge to find 
the right proportion for innovation with exploration and exploitation. The determining variables to balance in an adequate way can only be derived from a professional screening of the environment matched with the characteristics of the examined company (Hofbauer \& Bergmann, 2013). The question is whether there is a need to radically innovate, or is it sufficient to innovate incrementally.

\section{Radical or Incremental Innovation}

Figure 2 shows the results (output) of the combinations of technologies and markets (Fischer \& Lange, 2002; Hofbauer \& Sangl, 2011). Radical innovations result from explorative proceeding on the basis of pacemaking technologies targeting completely new markets. This leads ot completely new solutions for given problems (basic or fundamental innovation). Incremental innovations follow exploitative proceeding, in this case, existing solutions are developed further and improved step by step (improved innovation).

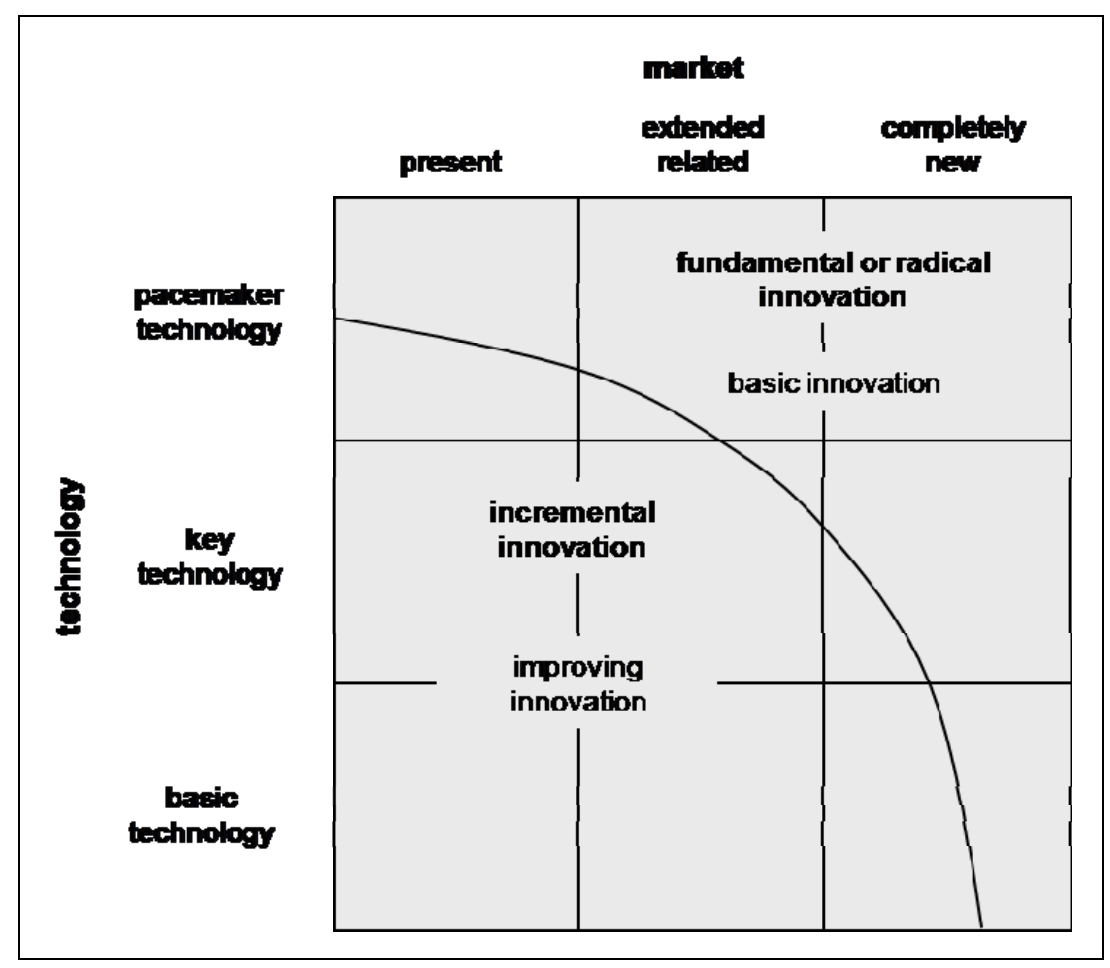

Figure 2. Radical and incremental innovations. Source: adopted and translated from Hofbauer and Sangl (2011).

\section{Framework of Innovation Management}

The analysis and discussion of scientific literature shows a variety of influencing factors on innovation management. Figure 3 displays the factors having influence on innovation management (Lavie et al., 2010). The part of the antecendents contains all influencing factors of the environment (external) and the company (internal). The findings of the analysis of the external and internal prerequisites affect the tradeoffs and the tendency towards exploration or exploitation. A substantial impact comes from the dynamism of the environment in terms of structural interruption and competitive pressure. For making the right decision, it is essential to identify the predictors of dynamism in time. Further factors like organization and management have an impact on the arrangement and balancing of innovation activities, too.

According to the input and management decision, a short or long term output will be visible in Figure 3. 


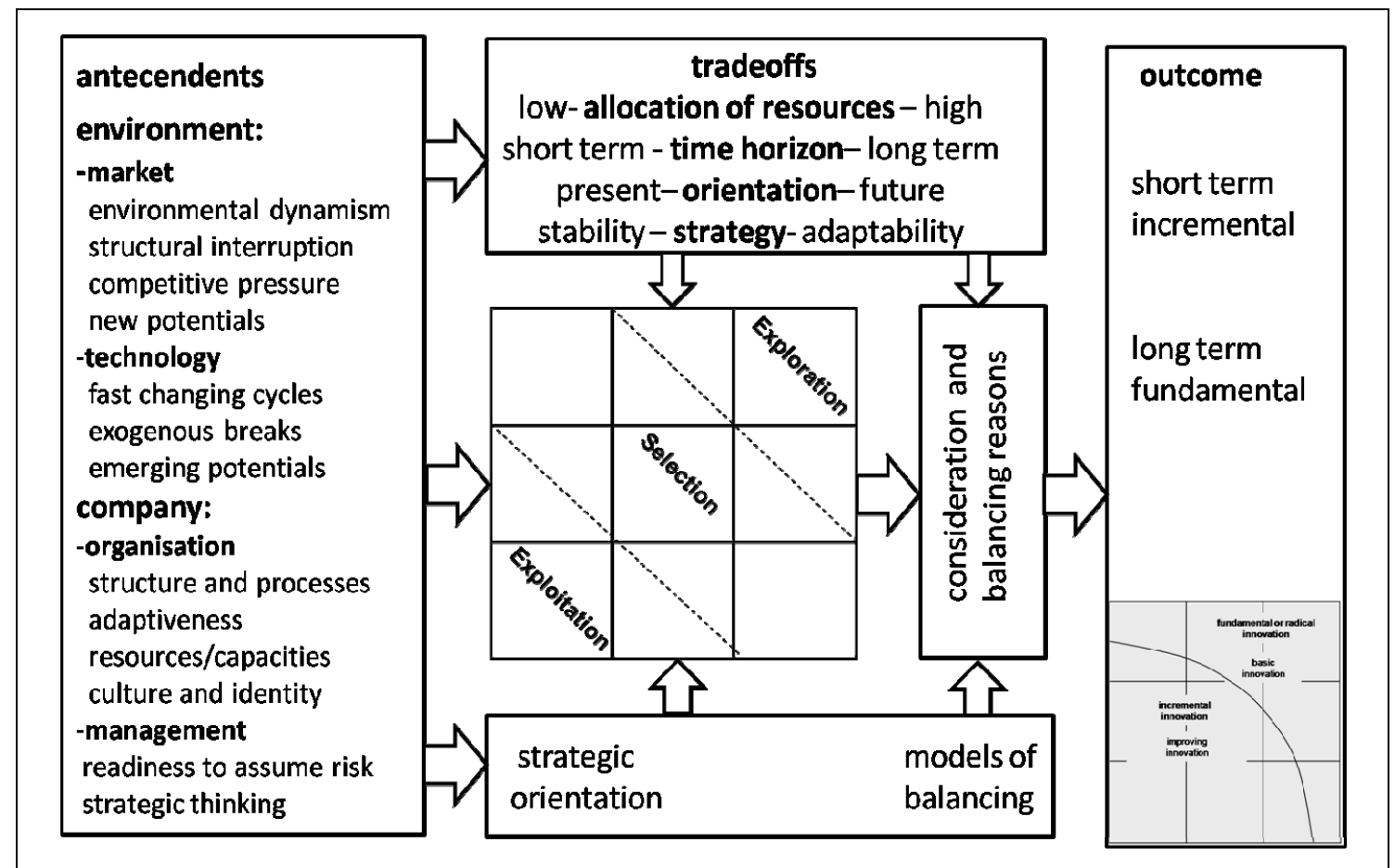

Figure 3. Factors of influence on innovation management with exploration and exploitation. Source: own graph, modified according to Lavie et al. (2010).

From the scientific point of view, two factors of influence can be identified:

- Company (organization and management)

- Environment (market and technology)

The analysis of these two dimensions establishes the understanding of the context and supports the decision making in the field of exploration and exploitation. Changes, ruptures, and crashes should be detected in time and consequences for the company should be identified. In doing this in a proper way, the management will get the right input for the strategic orientation in the very early phase of the product management (Hofbauer \& Bergmann, 2012). These changes may be caused by customer needs, new technologies, or changing demand.

\section{Innovation-Alignment-Portfolio}

In this chapter, the Innovation-Alignment-Portfolio (IAP) as a tool to support the decision towards exploration or exploitation in a comprehensible and balanced way will be introduced. As explained above, the essential dimensions of influence are company (internal) and environment (external). These two dimensions are the two axis, which build up the portfolio. The dimensions may be subdivided in various subdimensions, which represent the contemporary set of influencing factors.

Figure 4 shows the IAP exemplified with specific subdimensions. Depending on the results of the analysis, the company achieves one of the given categories (low-medium-high). Combining the categories for both dimensions, the company under review obtains a combination within the different quadrants. This position enables to derive strategies like exploration, selection, or exploitation. In case of selection, there is further research inevitable. 


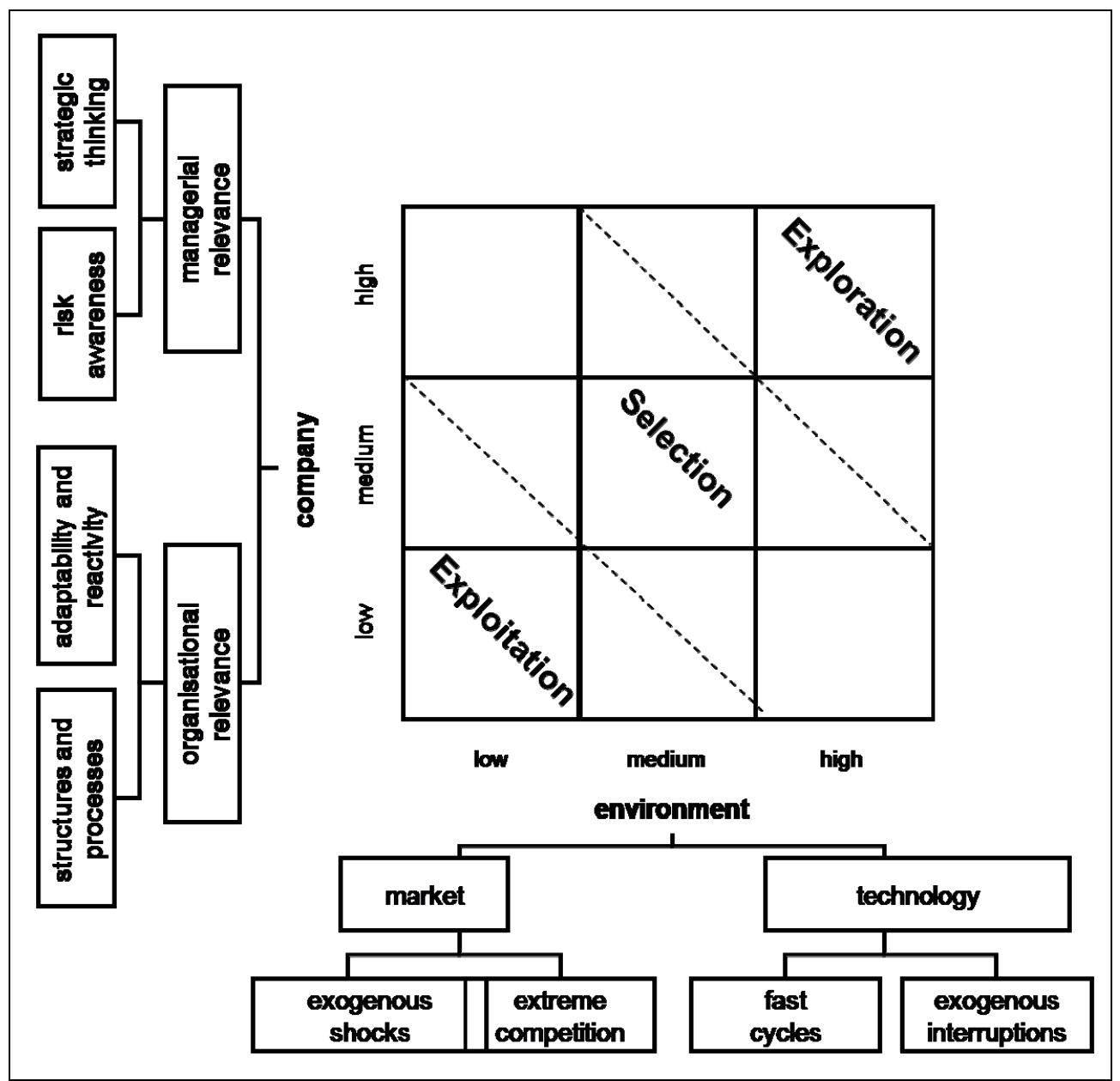

Figure 4. Innovation-Alignment-Portfolio. Source: own work.

\section{Conclusion}

Innovations ensure competitiveness, profitability, and survival of companies. Innovations are inevitable to protect and upgrade competitiveness. Rising dynamism of markets, increasing price pressure, intensification of global competition, hybrid forms of customer needs, and accumulated complexity of products are prevailing challenges for companies. To execute innovation management means a continuous decision process between exploration and exploitation.

The value added of this article is to introduce a tool in terms of the Innovation-Alignment-Portfolio (IAP), which helps to find a systematic way of balancing innovation activities. A systematic research about the framework of a company is necessary for a contemporary analysis of antecendents. This input provides magnitude and direction for the early phase "strategic orientation" of the product management cycle (Hofbauer \& Sangl, 2011) and gives by trend an indication for the proportion between exploration and exploitation. A permanent and consistent analysis of external (environment) and internal (company) factors is a crucial prerequisite for appropriate management decisions.

In this article, the Innovation-Alignment-Portfolio is introduced. It is a well-structured tool, which is based on an integrated and contemporary framework. 


\section{References}

Auh, S., \& Menguc, B. (2005). Balancing exploration and exploitation: The moderating role of competitive intensity. Journal of Business Research, 1652-1661.

Chen, E. L., \& Katila, R. (2008). Rival interpretations of balancing exploration and exploitation: Simultaneous or sequential? Handbook of Technology and Innovation Management, 198-214.

Fischer, J., \& Lange, U. (2002). Technologielebenszyklus und Technologiemanagement. In D. Specht and M. Möhrle (Eds.), Gabler Lexikon Technologie Management-Management von Innovationen und neuen Technologien im Unternehmen. Wiesbaden: Gabler.

Gandhi, S. J., \& Hofbauer, G. (2016). Understanding the entrepreneurial mindset as a key to innovation for business. Management of Organization in Real and Virtual Environment: Opportunities and Challenges. Politechnika Opolska, ISSN 1429-6063, Opole/Polen.

Gupta, A. K., Smith, K. G., \& Shalley, C. E. (2006). The interplay between exploration and exploitation. Academy of Management Journal, 49(4), 693-706.

Hofbauer, G. (2013). Innovations-und Technologiemanagement im Marketing. In G. Hofbauer, A. Pattloch, and M. Stumpf (Eds.), Marketing in Forschung und Praxis (pp. 31-54), Berlin: Uni-Ed.

Hofbauer, G., \& Bergmann. S. (2012). Prinzipien des Innovations-und Technologiemanagements, Arbeitsberichte-Working Papers, Hochschule Ingolstadt, Heft Nr. 23, ISSN 1612-6483, Ingolstadt 2012.

Hofbauer, G., \& Bergmann. S. (2013). Professionelles Controlling in Marketing und Vertrieb, ein integrierter Ansatz mit Kennzahlen und Checklisten. Erlangen: Publicis.

Hofbauer, G., \& Sangl, A. (2011). Professionelles Produktmanagement—Der prozessorientierte Ansatz, Rahmenbedingungen und Strategien (2nd ed.). Erlangen: Publicis.

Hofbauer, G., Körner, R., Nikolaus, U., \& Poost, A. (2009). Marketing von Innovationen-Strategien und Mechanismen zur Durchsetzung von Innovationen. Stuttgart: Kohlhammer.

Lavie, D., \& Rosenkopf, L. (2006). Balancing exploration and exploitation in alliance formation. Academy of Management Journal, 49(4), 797-818.

Lavie, D., Stettner, U., \& Tushman, M. L. (2010). Exploration and exploitation within and across organizations. The Academy of Management Annals, 4(1), 109-155.

Lubatkin, M. H., Simsek, Z., Ling Y., \& Veiga, J. F. (2006). Ambidexterity and performance in small-to-medium-sized firms: The pivotal role of top management team behavioral integration. Journal of Management, 646-672.

March, J. G. (1991). Exploration and exploitation in organizational learning. Organization Science, 2(1), 71-87.

O'Reilly, C. A., \& Tushman, M. L. (2004). The ambidextrous organization. Harvard Business Review, 82(4), 1-10.

Proff, H., \& Haberle, K. (2010). Begrenzung von Ambidextrie durch konsistentes dynamisches Management. Jahrbuch Strategisches Kompetenz Management, Band 4: “Ambidextrie": Der unternehmerische Drahtseilakt zwischen Ressourcenexploration und-exploitation, 86-89, Mering: Rainer Hamp Verlag.

Siemens, A. G. (2014). Interactive Foresight Session: Trend Monitoring in Action.

Wollersheim, J. (2010). Exploration und Exploitation als zwei Seiten derselben Medaille: Eine systematische Zusammenführung bestehender Konzepte zur Förderung von Ambidextrie im Unternehmen. Jahrbuch Strategisches Kompetenz Management, Band 4: "Ambidextrie": Der unternehmerische Drahtseilakt zwischen Ressourcenexploration und-exploitation, 1-26, Mering: Rainer Hamp Verlag. 